\title{
Research on Stress Among the Engineering College Students in Coimbatore, India
}

\author{
R.Mayildurai, R.Ashokkumar, K.Karthik, M. Shanmugaprakash
}

\begin{abstract}
The students are generally affected by stress especially in professional courses like medical, engineering are affected by higher stress, this leads to psychological problems such as high amount of depression, nervousness, cardiac problems etc.,. Mental health among the students indicates growing concern along with opportunity, because of the large number of people who could be reached during an important period of life. College premises, by their scholarly nature, are also well positioned to develop, evaluate, and disseminate best practices. In short, colleges offer a unique opportunity to address one of the most significant public health problems among late adolescents and young adults. Busy schedules crammed with curricular, co-curricular and extracurricular activities can affect the student's physical and mental health, especially on delayed eating and improper and less sleeping. These stressors can compound over time, leading to even greater levels of stress. College premises, by their scholarly nature, are also well positioned to develop, evaluate, and disseminate best practices. In short, colleges offer a unique opportunity to address one of the most significant public health problems among late adolescents and young adults. This study aims to analyse the stress among the engineering students from sample survey. A quantitative method was used in gathering and analysing the data by distributing questionnaires to the students. The results obtained were analysed for different factors that cause stress among students.
\end{abstract}

Key words- Reasons for stress, Students, Effects

\section{INTRODUCTION}

Stress is a state of mental strain or pressure resulting from adverse or demanding circumstances. Normally stress is unavoidable, and is part of our life. Physiologically, stressrelated diseases in the form reproduction, cardiovascular, metabolism and gastrointestinal diseases are determined by great areas of genetic and developmental factors which are different from a person to a person but also symptoms of this disease may be similar sometimes among individuals. There are many types of stress, and it is generally grouped in to two types. That is good and bad stress. Good stress also termed as eustress and it is motivates the person to reach the goals, eventually leading to more happiness, success, or fulfilment. These are generally relatively short bouts of stress and provide motivation to get something done or overcome an obstacle. Bad stress also called as distress and it can be short-term or long-term. It is frequently escorted by the thoughts of helplessness because don't have a lot of

Revised Manuscript Received on August 14, 2019.

R.Mayildurai1, Department of Chemistry, Kumaraguru College of Technology, Coimbatore. T.N, India (rmdurai79@gmail.com)

R.Ashokkumar, Department of Chemistry, Kumaraguru College of Technology, Coimbatore. T.N, India

K.Karthik, Department of Chemistry, Kumaraguru College of Technology, Coimbatore. T.N, India

M. Shanmugaprakash, Department of Biotechnology, Kumaraguru College of Technology, Coimbatore. T.N, India control over what's happening and may begin to feel compressed or trapped. The stress among the people due to various reasons such as employment, income, societal behavior, health nature etc. Indeed, students have a unique cluster of stressful experiences. Student's academic performances can be affected by many factors. The recent studies on stress shows that students are facing much stress than the other and they can't able to manage the stress this leads to make them kill oneself [1]. It is because of reasons like leaving the home for education, feeling intense pressure to get good marks in the examination, to get right career, trying to begin a romantic/social life, dealing with costs of institution, adapting to a new environment, balancing a heavy work load, making new friends, becoming more independent and dealing with myriad of other issues [2,3]. Looking from a closer perspective, the college students encounters a number of challenges in his day to day life, therefore the whole idea of an existing and vibrant college life is unveiled by these challenges which in turn contribute to stress and if not dealt with can only escalate and hamper their academic performance, emotional and social well-being. Deprived fitness were also related with high levels of stress [4]. The consumption of junk food, laziness to work out physical exercise and less likely to obtain sufficient amounts of sleep also cause stress among the students. There is a debate always on the relationship between opposite gender, stress appraisal, and coping strategy use. One of the reason for the stress among student is at this level of growth are pre-occupied with the development of association with opposite gender [5]. They want to belong and be accepted by their peers. Making new friends is another source for college students $[6,7]$. According to reports it has found that female students were affected more stress than male students since the female students were managed their stress emotionally by expressing feelings, seeking emotional support, denial, acceptance etc., and the male students are occasionally consumed drugs to manage their stress this is alarm for the society $[8,9]$. Every student has a life outside the academic curriculum and environment. When a student has to compromise and use their personal time for other activities for studies, they turn to get bored and lose interest in studies $[10,11]$. At the long run, this situation stresses them up which causes them to lose focus on academic work. Numerous studies have been taken for the analysis of stress among the students, as far our knowledge no one has report the stress on the engineering college students exclusively.

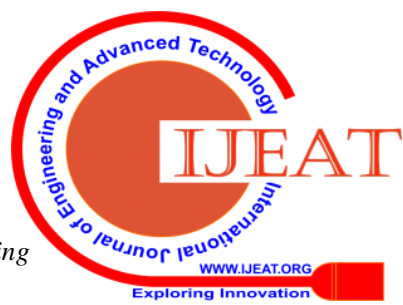


This study have shown the pervasiveness of stress among students studying engineering courses in Coimbatore, India.

\section{METHODOLOGY}

This study attempts to identify the causes of stress on engineering students, In view of the purpose of this study, a questionnaire was structured carefully. Simple and easy words were used so that student respondents can easily understand as well as answer the questions. Possible answers were provided to enable the students to tick which ever answer they find suitable in terms of their response to the question. The questionnaire comprises of twenty main question and fifteen sub questions which are relate with main questions. The questionnaire were circulated among the engineering college students in Coimbatore district, Tamilnadu, India. More than three hundred responses received from the students and the data are recorded. In this, responses are includes all branches of engineering courses, different regions of the institutions located in Coimbatore district.

\section{RESULTS AND DISCUSSION}

The respondent for this survey of students aged between 17 and 19 years. $80 \%$ of the students are different native came to Coimbatore for their higher studies and they are stayed in the institution hostel. In this category $27 \%$ of the student's native located in the village areas. The rest of the students from town and city locality. $73 \%$ of the student's institution located in the city limit (Figure 1). The transition from rural to urban is the one of the challenge for the students in the first of their study. Here students move with fellow student is a considerable factor. Most of the students from rural background are not able to mingle with the home town students.

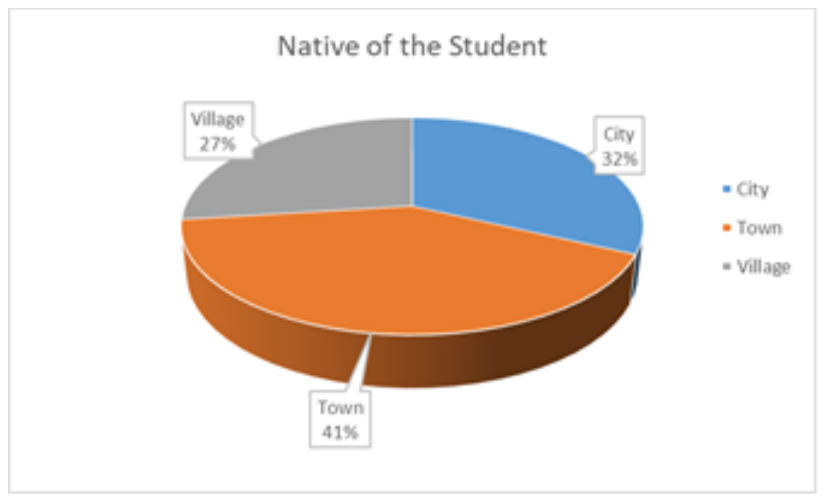

Figure 1: Schematic view of student's native

The majority of the day scholar students are express their preference to come to college on their own vehicle. But only $35 \%$ of the students came to the institution by their own vehicle. $50 \%$ of the students reach the college by college bus. Their parents sent them by the institution vehicle since they felt that is the safest mode of transport. Here the challenge for the student is to pick the institution vehicle on time. Most of the students are habit of late to the bed for sleep and very late to wake up, this leads to anxiety in the morning itself. If the parents allowed them to use their own vehicle most of the students doesn't take care of the traffic rules. Around $15 \%$ of the students use public transport to reach the college (Figure 2). Using public transport in peak hours is a challenging task due to overcrowding.

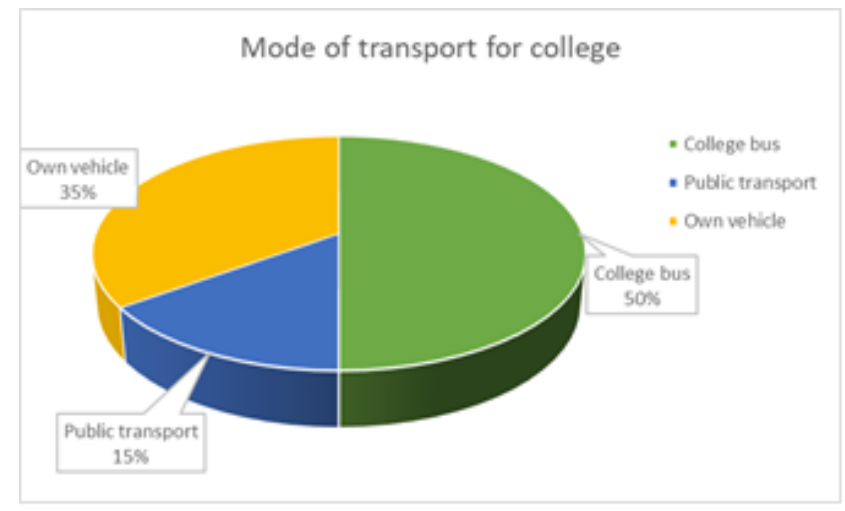

Figure 2: Student's access to college

Student should concentrate on extra-curricular and cocurricular activities, and thus should be the main objective For that financial comfort is one of the important tool. This survey states that only $65 \%$ of the students express their satisfaction on their family income. $35 \%$ of the students are feel unhappy with their family income. This will leads to some disturbance on the students mind and later it is converted into stress. The survey report also reveals that 25 $\%$ of the students having specific responsibility in their family such as helping parents for family business, take care of siblings, take care of grandparents etc. $10 \%$ of the students can earn money for their educational expenses through part time jobs (Figure 3).

Family Resposiblity

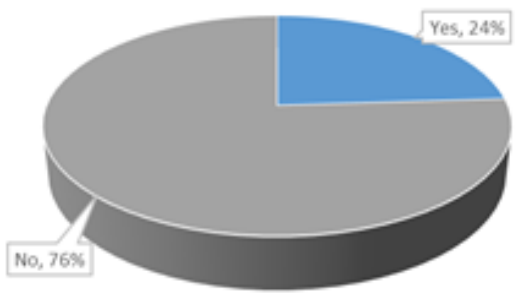

Figure 3: Graphical view of student's responsibility towards family

$75 \%$ of the student's said that their educational expenses can be taken care of their parents. $21 \%$ of the students replied that their expenses meet out by availing educational loan from the banks. Rest of the students can be sponsored by the external agencies. Once taking two or more responsibilities simultaneously will leads to nervousness, fear, anxiety and finally stress. So financial un-comfort is one of the reason for the stress among the students.

$70 \%$ of the students only stated that they are choosing the course of their own interest, rest of the students chose the 
course because of the influence of parents and others (Figure 4). Parents should properly guide their wards before choose the course of study or else they will feel disturbed in the college atmosphere. $96 \%$ of the students' state that the parents will help to achieve their dreams that shows their expectation towards their parents.

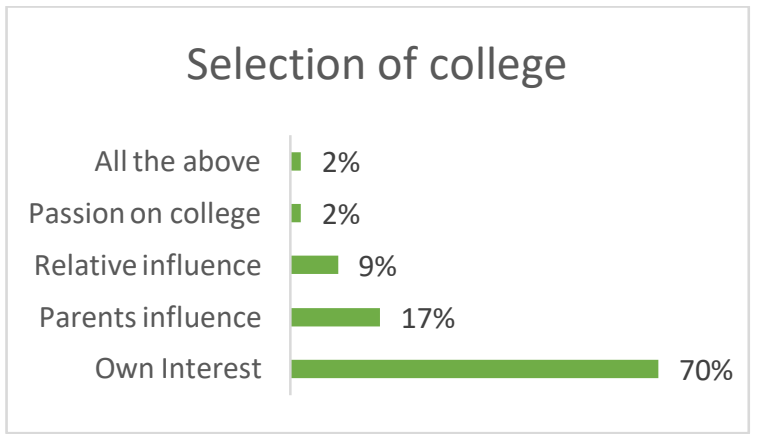

Figure 4: Student's response on selection of college

Society is one of the major factor for the stress free nature among the people. If small societal changes may create lot influence on people mind. This report shows that the $15 \%$ of the responding students were stated that their attitude influenced by societal incidents. They specify the various incidents such as poverty, feminism, male chauvinism, bribe etc. They expressed that they feel discomfort on the societal activities that leads to stress on their mind. In the college premises $79 \%$ of the responded students expressed that they were comfortable with their class mates. Rest of the students have not able to associate with all the students. The reason they stated are some students form group, financial background, individual attitude, lack of understanding etc. Apart from these some of the societal activities also makes the students as divided.

$66 \%$ of the students state that they feel free to approach the opposite gender for their academic needs. $20 \%$ of the student states that they were feel shy to approach the opposite gender and $14 \%$ of the student state that they were not approaching. In this category the $20 \%$ of the students feel stressed because of their shyness and they express their inability on the others through anger or make others irritated. This kind of attitude among the students should be addressed in a proper way.

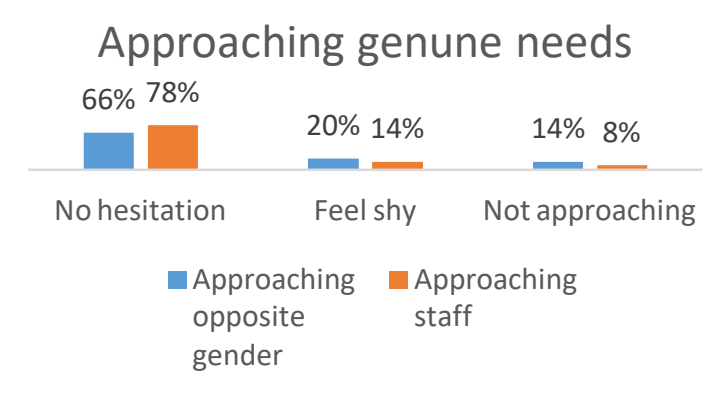

\section{Figure 5: Approaching Opposite gender/ academic staff for genuine needs}

$78 \%$ of the students expressed that they easily approach the faculty for their genuine academic needs, $14 \%$ of the students feel shy to approach the faculty and $8 \%$ told that they were not approaching. This is also one of the important issue to be addressed among the students. Students should be motivated to approach the faculty for their genuine needs since they are mentors for them. Because of this shy attitude and not approaching attitude creates stress on the younger mind (Figure 5).

\section{CONCLUSION}

From the above study it is inferred that the students of engineering courses are distressed in a significant level. Students with free mind with comfortable atmosphere can get lime light. From the above discussions it is observed that the factors like, societal influence, financial status academic environment are influence students attitude. To overcome these kind of stress among the engineering students a proper counselling should be offered to them and develop confidence on their minds to manage the difficulties during their college days. In addition to this student should be mould to find the solution for their complexity due to stress. This survey shows new insight in to the stress related problems faced by engineering students and this help to rectify those problem and build a healthier future younger generations.

\section{REFERENCES}

1. Lumley, M. A., \& Provenzano, K. M. (2003). Stress management through written emotional disclosure improves academic performance among college students with physical symptoms. Journal of Educational Psychology, 95(3), 641-649.

2. Struthers, C. W., Perry, R. P., \& Menec, V. H. (2000). An examination of the relationship among academic stress, coping, motivation and performance in college. Research in Higher Education, 41(5), 581-592.

3. Abouserie, R. (1994). Sources and levels of stress in relation to locus of control and self-esteem in university students. Educational Psychology, 14(3), 323-330.

4. Blankstein, K. R., Flett, G. L., \& Koledin, S. (1991). The brief college student hassles scale: Development, validation, and relation with pessimism. Journal of College Student Development, 32(3), 258-264.

5. Crespi, T. D., \& Becker, J. T. (1999). Mental health interventions for college students: Facing the family treatment crisis. Family Therapy, 26(3), 141-147.

6. Bailey, R. C., \& Miller, C. (1998). Life satisfaction and life demands in college students. Social Behavior and Personality, 26, 51-56.

7. Chang, E. C. (2001). Life stress and depressed mood among adolescents: Examining a cognitive-affective mediation model. Journal of Social \& Clinical Psychology, 20(3), 416-429.

8. Dyson, R., \& Renk, K. (2006). Freshmen adaptation to university life: Depressive symptoms, stress, and coping. Journal of Clinical Psychology, 62(10), 1231-1244.

9. Edwards, K. J., Hershberger, P. J., Russell, R. K., \& Markert, R. J. (2001). Stress, negative social exchange, and health symptoms in university students. Journal of American College Health, 50(2), 75-79

10. Lumley, M. A., \& Provenzano, K. M. (2003). Stress management through written emotional disclosure improves academic performance among college students with physical symptoms. Journal of Educational Psychology, 95(3), 641-649.

11. Pritchard, M. E., \& Wilson, G. (2006). Do coping styles change during the first semester of college? Journal of Social Psychology, 146(1), 125-127. 